\title{
Uterine Rupture in Labour: A Continuing Obstetric Challenge in Developing Countries - The Benin Experience
}

\author{
A. E. Ehigiegbaa and I. S. Adeyemoa
}

\begin{abstract}
We report 51 cases of uterine rupture following unsupervised labour and/or the use of oxytocin in stimulated labour over a twelve-year period (between 1991 and 2002). During the period under review, there were 16041 deliveries, giving a ruptured uterus rate of 3.18/ 1000 with booked and unbooked patients being 1.87 and 9.63 respectively. This rate, however, rose astronomically between 1998 and 2000 to three times the yearly average, coinciding with a new departmental protocol on oxytocin use in labour. About 65\% of the cases were unbooked, and more than $80 \%$ of the uterine rupture occurred before the patients presented to our delivery suites. Most of the cases occurred among those between Para 1 and 4 (70.4\%), while 29.6\% occurred among the grandmultiparas. A previous uterine scar was associated with $68.2 \%$ of the cases, while prolonged obstructed labour occurred in $38.6 \%$. Oxytocin use was thought to be responsible for $31.8 \%$ of cases. Misoprostol was responsible for one case. Augmented labour accounted for $50 \%$ of the indication for oxytocin use. The diagnosis of ruptured uterus was pre-operative in $85 \%$ of cases and intra-operative in the rest. There was no post-partum diagnosis of ruptured uterus in the series. About $50 \%$ of the patients had repair only while about 27\% had hysterectomy, and 9 patients had repair plus tubal ligation. The most common associated injury found at surgery was broad ligament haematoma, closely followed by rupture of the urinary bladder. Maternal mortality in this series was $6.8 \%$. The problems associated with the diagnosis and management of uterine rupture in a developing country is discussed. The need for judicious use of oxytocin, especially in patients with previous uterine scar and in grand-multiparas, and the adequate deployment of experienced obstetricians and experienced midwives in the delivery suits is discussed.
\end{abstract}

\section{INTRODUCTION}

Rupture of the uterus constitutes one of the most tragic obstetric catastrophes to befall a woman and a great threat to the survival of the

KEY WoRDs: Uterine rupture, Obstructed labour, Oxytocin use, Grand multiparity, Maternal mortality

aDepartment of Obstetrics and Gynaecology, University of Benin Teaching Hospital, Benin City, Edo State, Nigeria.

Correspondence: Dr. A. E. Ehigiegba, Department of Obstetrics and Gynaecology, University of Benin Teaching Hospital, PMB 1111, Benin City, Edo State, Nigeria.

( ) CMS UNIBEN JMBR 2006; 5(1): 44-50 woman and her fetus. ${ }^{1}$ The incidence of ruptured uterus varies from country to country, depending on the predominant etiologic factors in such areas. Reports from various authors in Nigeria and other parts of Africa in the last two decades have put the incidence between $2.4-8.9$ per 1,000 deliveries. ${ }^{2,3}$, and 4 . In contrast, incidences in developed countries range between 0.2 and 0.4 per 1,000 deliveries. ${ }^{5,6}$. The high incidence of this condition in Africa is attributed to the general aversion of women in the developing countries to abdominal deliveries, often as a result of ineffective or absent antenatal care. ${ }^{7,8}$ 
Uterine Rupture in Labour: A Continuing Obstetric Challenge in Developing Countries - The Benin Experience 45

Most cases of uterine rupture in developing countries are primarily spontaneous with prolonged/obstructed labour being the commonest etiologic factor. ${ }^{3,4}$. Rupture of the uterus is a significant cause of maternal mortality; the main causes of death include shock (haemorrhagic or Septicaemic), pulmonary embolism and occasionally disseminated intravascular coagulation and Mendelson's syndrome. 5, 8, 9. A high perinatal mortality is the hallmark of ruptured uterus with reported incidences ranging from 75 to $93 \% .4,8,9$,

The aims of this study are:

(i) To determine the incidence and trends of ruptured uterus at the University of Benin Teaching Hospital (UBTH) between 1991 and 2002,

(ii) Determine the various etiologic factors, especially among the booked and unbooked categories,

(iii) Assess the modalities of management and outcome, and

(iv) Finally, recommend ways to prevent uterine rupture and improve the outcome cases of uterine rupture in the hospital

\section{STUDY DESIGN :}

The study was retrospective and all cases of ruptured uterus that were managed in U.B.T.H. between 1991 and 2002 were included in the study.

\section{MATERIALS AND METHODS}

All cases of ruptured uterus managed at the University of Benin Teaching Hospital (UBTH) from January 1991 to December 2002 were reviewed. Relevant data on age, parity, educational level, booking status, etiologic factors, previous records of caesarean sections, operative findings and type of surgery, blood transfusions, post-operative complications and post-operative management were obtained from the case records. The total number of deliveries for the entire study period was also determined. The findings were analysed and where appropriate, subjected to statistical analysis using the statistical padkage for social sciences. Statistical significance was set at $\mathrm{P}<0.05$ where applicable.

Table 1: Yearly Rate of Uterine Rupture

\begin{tabular}{|c|c|c|c|c|c|c|c|c|}
\hline \multirow[b]{2}{*}{ Year } & \multicolumn{3}{|c|}{ Total Deliveries } & \multicolumn{2}{|c|}{$\begin{array}{l}\text { Cases (Ruptured } \\
\text { Uterus) }\end{array}$} & \multicolumn{2}{|c|}{$\begin{array}{l}\text { No Per } 1000 \\
\text { Deliveries }\end{array}$} & \multirow[t]{2}{*}{$\begin{array}{l}\text { Total } \\
\text { Rate }\end{array}$} \\
\hline & Total & Booked & Unbooked & Booked & Unbooked & Booked & Unbooked & \\
\hline 1991 & 1744 & 1444 & 300 & 3 & 3 & 2.07 & 10.00 & 3.44 \\
\hline 1992 & 1747 & 1454 & 293 & 2 & 3 & 1.37 & 10.23 & 2.86 \\
\hline 1993 & 1748 & 1471 & 271 & 1 & 1 & 0.68 & 3.69 & 1.14 \\
\hline 1994 & 1756 & 1499 & 307 & 2 & 3 & 1.33 & 9.98 & 2.85 \\
\hline 1995 & 1700 & 1400 & 300 & 1 & 1 & 0.71 & 3.33 & 1.18 \\
\hline 1996 & 1691 & 1466 & 255 & 0 & 2 & 0.00 & 7.84 & 1.18 \\
\hline 1997 & 1207 & 1012 & 195 & 0 & 1 & 0.00 & 5.13 & 0.83 \\
\hline 1998 & 852 & 690 & 162 & 4 & 1 & 5.70 & 6.17 & 5.86 \\
\hline 1999 & 839 & 684 & 155 & 5 & 2 & 7.30 & 12.90 & 8.34 \\
\hline 2000 & 792 & 652 & 140 & 4 & 3 & 6.13 & 21.42 & 8.83 \\
\hline 2001 & 975 & 816 & 159 & 2 & 2 & 2.45 & 12.58 & 4.10 \\
\hline 2002 & 990 & 838 & 152 & 1 & 4 & 1.19 & 26.31 & 5.05 \\
\hline Total & 16041 & 13343 & 2698 & 25 & 26 & 1.87 & 9.63 & 3.18 \\
\hline
\end{tabular}




\section{RESULTS}

There were 51 cases of ruptured uterus during the 12-year period while the total number of deliveries during the same period was 16,041, giving a total incidence of 3.1 per 1,000 deliveries (or 1: 315 deliveries). Table 1 shows that the yearly incidence per thousand ranged from 0.831997 to 8.86 in 1998. A sudden rise was observed from 1998 (5.86 per 1000) to 2000 (8.83 per 1,000 ). The unbooked clients accounted for $54.9 \%$ of all cases. This was statistically significant $(P<0.05)$. However $84 \%$ of all cases of ruptured uterus occurred outside the hospital. The rate specific incidence between booked and unbooked patients were 1.87 and 9.63 per 1000 deliveries respectively. This was statistically significant $(\mathrm{P}<0.001)$.

The diagnosis of uterine rupture was made pre-operatively in $90 \%$ of the cases while the remaining $10 \%$ were made intra-operatively. Thirty-six (70.6\%) occurred in women of parities 1 to 5 grandmultiparity constituted only $29.6 \%$ of cases. The various etiologic factors associated with ruptured uterus are outlined in Table 2. Although many patients had more than one etiologic factor, the most frequent factor was a previous uterine scar
(68.2\%), followed by prolonged obstructed labour (38.6\%), and $31.8 \%$ was oxytocin related. There was a case of Misoprostone induced rupture which occurred after 3 insertions of 75microgrammes of Misoprostone tablet. The dose of Misoprostone for inducing labor was subsequently reduced to 50microgrammes in our Labor Ward protocol.

From Table 2, it can be seen that whereas oxytocin and misoprostol (33.3\%) were responsible for most cases of uterine rupture in the booked patients, lack of ante natal care resulting in prolonged obstructed labor (40\%) was responsible for uterine rupture in the unbooked group.

Among the clients with oxytocin induced ruptures $85.8 \%$ were Para 1-4 while only 14.2\% were grandmultiparas. This difference was statistically significant $(\mathrm{P}<0.05)$. Augmentation and induction of labour each represented $50 \%$ of the indications for oxytocin use in those with oxytocin related rupture. The minimum and maximum oxytocin infusion rate at which the rupture occurred was 8mu/ $\mathrm{min}$. and $32 \mathrm{mu} / \mathrm{min}$. respectively.

In the surgical management of these patients, 25 (49\%) had repair of the ruptured uterus. Hysterectomy was performed in 14

Table 2: Associated Causes of Rupture in Booked and Unbooked Patients

\begin{tabular}{|l|l|l|l|l|}
\hline Associated Cause & Booked & Unbooked & Total* & $\%$ * \\
\hline One Previous Caesarean Section & 11 & 12 & 23 & 52.3 \\
\hline Two Previous Caesarean Sections & 3 & 3 & 6 & 13.6 \\
\hline Three Previous Caesarean Sections & 0 & 1 & 1 & 2.3 \\
\hline Prolonged Ubstructed Labour & 1 & 16 & 17 & 38.6 \\
\hline Oxytocin Induction / Augumentation & 13 & 1 & 14 & 31.8 \\
\hline Misoprostol Induction & 1 & 0 & 1 & 2.3 \\
\hline Vacuum Extraction & 1 & 2 & 3 & 6.8 \\
\hline Forceps Delivery & 1 & 0 & 1 & 2.3 \\
\hline Breech Extraction & 0 & 1 & 1 & 2.3 \\
\hline External Cephalic Version & 0 & 1 & 1 & 2.3 \\
\hline Shoulder Dystocia & 0 & 2 & 2 & 4.5 \\
\hline Impacted Transverse Lie With Prolaped Hand & 0 & 3 & 3 & 6.8 \\
\hline
\end{tabular}

*The total percentage is $>100$ as most patients had more than one associated cause.

( C CMS UNIBEN JMBR 2006; 5 (1) : 44-50 
Uterine Rupture in Labour: A Continuing Obstetric Challenge in Developing Countries - The Benin Experience 47

patients (27.5\%) out of whom 4 had total hysterectomy and 10 sub-total hysterectomies. Twelve patients had repair with bilateral tubal ligation. Associated injuries included ruptured urinary bladder (11.4\%) , and cervical laceration (13.6\%). There was a case of ureteric injury that was successfully repaired. The average blood loss was 3250ml. with a range of $500 \mathrm{ml}$ to $5,000 \mathrm{ml}$. Most of the patients (90.9\%) had blood transfusions either intra-operatively or post-operatively.

There were a total of 3 maternal deaths giving a case fatality rate of 5.9\%. Two of the patients were unbooked while one was booked. The causes of maternal death were haemorrhagic shock, septicaemia and disseminated intravascular coagulation. The foetal outcome was poor with only 22 (43.1\%) survivors, $73.6 \%$ of whom were booked. The perinatal mortality was 568.2/1000.

\section{DISCUSSION}

The incidence of uterine rupture varies from one obstetric population to the other and depends on the obstetric risk factors operating in the given population, the availability of obstetric care facilities and the level of utilisation of such facilities. ${ }^{4,5,88 . ~ I n ~ t h i s ~ s t u d y, ~}$ the total incidence of ruptured uterus was 3.18 per 1,000 deliveries. This figure is similar to incidences reported in most centres in Nigeria, 10, 11, but slightly higher than an earlier study at the same centre by Oronsaye et al, ${ }^{3}$ in which an incidence of 1 in 430 deliveries was reported. Higher figures have also been observed in studies done in other centres in Nigeria. 4, 8, 11. This rising trend may be due to the progressive decline in the socio-economic status of Nigerians in general and women in particular during the study period, as well as the increasing cost of medical services in most tertiary centres in the country. The decline of the Nigerian economy has led to an increasing number of unbooked women or clinic defaulters among those that booked. This tendency of booked clients to default from the antenatal clinic of a tertiary hospital and try delivery elsewhere for economic reasons was clearly shown in this study where $84 \%$ of the ruptures occurred outside the hospital. This is also reflected in a steady drop in the yearly delivery rate as evidenced from this study. Other authors have made similar observations. ${ }^{4,8}$, and 12 .

The socio-cultural aversion of Nigerian women to abdominal delivery or a repeat surgery may be an additional factor. Thus many of them would attempt vaginal delivery elsewhere, especially in prayer homes, only to present late in the hospital with avoidable complications. This was observed in this study where majority of the patients with previous scars were either unbooked or clinic defaulters. Studies done elsewhere ${ }^{4,}$ 7, 13, 14, have also confirmed this finding. In this study, however, the sharpest increase in our rate, especially in cases of previous scars and grandmultiparity, coincided with a new labour ward policy that significantly increased the total dose of oxytocin use. The policy has since been reverted. Nevertheless, when judiciously used and properly monitored, oxytocin has been shown to be safe in patients with a previous uterine scar ${ }^{15,}$ 16, and 17. However, the high incidence of oxytocin induced ruptures in this study (31.8\%) is much higher than most studies done earlier in the same department or elsewhere, with incidences of between 4.5 to $18.6 \%$ having been reported ${ }^{3,8}$, 12. A significant proportion of the women who had uterine rupture were Para 1 (29.6\%), and these were patients with one previous caesarean section who were either subjected to oxytocics or had prolonged, obstructed labour.

Increasing parity is known to be an important etiologic factor in uterine ruptures. Grandmultiparas are especially prone and constitute a major risk group 5, 6, 7. In this study, only $29.6 \%$ of the patients who suffered uterine rupture were grandmultiparas. This figure is similar to the findings of similar studies ${ }^{4,10,11,14 .}$ The decision on

(ㅇ CMS UNIBEN JMBR 2006; 5 (1) : 43-49 
vaginal birth and oxytocin usage following a previous caesarean section should be taken by an experienced obstetrician.

Many cases of uterine rupture are associated with a combination of risk factors as was demonstrated in this study. However, the most frequent single identified etiologic factor was a previous caesarean section scar (68.2\% of the cases) , followed by prolonged obstructed labour and oxytocin use. Though this finding is similar to the findings of Oronsaye et $a l^{3}$ and Konje et $a l^{8}$, it is in sharp contrast to the findings of the majority of the studies done in Nigeria where prolonged obstructed labour was found to be the most common associated etiologic factor ${ }^{4}, 7,11$, and 19.

The clinical presentation of ruptured uterus depends on the site and nature of the rupture, the time of presentation to the hospital, the amount of blood loss and the presence of other associated complications. 6, 7, 16. Thus, a high index of suspicion needs to be maintained. No case of rupture in the puerperiumwas picked up in this series because the routine exploration of the lower uterine segment in patients with vaginal delivery after a caesarean section is not practiced in this centre. In this study, the average interval between diagnosis and intervention was 1 hour, 48 minutes. Delay in surgical intervention after diagnosis is an important factor associated with increased matemal and fetal morbidity and mortality. Some identifiable causes of delay in previous studies were poor financial state of the women, inadequate blood banking facilities and delay in dotaining consent for surgery ${ }^{8,9}, 10$,

The lower uterine segment was the commonest site of rupture in this study, accounting for up to $79.5 \%$, with $63.6 \%$ being anterior and transverse. This is obviously related to the presence of previous lower segment transverse uterine scar.

Generally, the choice of surgery depends on the site and extent of rupture, the condition of the patient at the time of presentation; the patient's parity, the choice and experience of (.) CMS UNIBEN JMBR 2006; 5 (1): 44-50 the surgeon as well as the socio-cultural peculiarity of the areas of practice. ${ }^{8,} 14,20$. The commonest surgical treatment in this study was repair of the uterus alone, followed by a hysterectomy. Repair with bilateral tubal ligation was the least common. This is the trend in most studies done in Nigeria and indeed Africa. 4, 8, 14, 19, 20. Hysterectomy was however, the commonest mode of surgery in some studies ${ }^{11,12,21 .}$ Repair only was offered to young women and those of low parity whose ruptures were in the anterior lower segment and were amenable to adequate repair and devoid of infection. Repair with tubal ligation was performed for those patients who were grandmultiparous or those with posterior or more extensive ruptures in a poor clinical state. This approach is similar to those of other authors ${ }^{3,}$ 8, 19, 20.

Hysterectomy was performed for those with combined anterior and posterior ruptures. Most of these patients had associated laceration into the broad ligament with involvement of the uterine arteries or its branches and associated severe and sometimes uncontrollable haemorrhage. These indications for hysterectomies are similar to

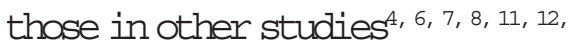

Ruptured uterus is associated with a significant matemal morbidity. In this series, haemorrhage was the most common complication with many patients presenting in shock. The average blood loss was 3.3 litres with over $90 \%$ of them requiring blood transfusion either intra-operatively or postoperatively. Generally, post-operative complications were commoner in patients who had prolonged labour, severe anaemia, florid infection and hysterectomy.

Ruptured uterus remains a major cause of maternal mortality and ranks among the five major causes of maternal deaths in developing countries (W.H.O., 1994). We recorded three maternal deaths (6.8\%). This incidence is similar to those of Oronsaye et $a l,{ }^{3}$ and Konje et $a l^{8}$, (1990) but lower than those reported

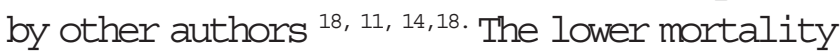


Uterine Rupture in Labour: A Continuing Obstetric Challenge in Developing Countries - The Benin Experience 49

recorded in this study was probably due to the early presentation and diagnosis and the prompt and aggressive surgical intervention. Ruptured uterus is often associated with a poor fetal outcome. The perinatal mortality of 568.2/1000 (most of which occurred in unbooked clients) in our series was quite high but similar to the results of other series 3, 8, 19.

The fact that this trend is not declining calls for a lot of concern. The contribution of a previous caesarean section scar calls for proper evaluation of such clients by experienced obstetricians before oxytocin use. The importance of making lifesaving medical technology available in the delivery suits of tertiary medical institutions, deployment of dedicated senior doctors (anaesthetists and obstetricians) and experienced midwives to the delivery suits as a way of adequately managing labour complications such as uterine rupture in labour cannot be overemphasised. Unless this problem is given its desired attention by health planners, uterine rupture in labour will remain with us for a long time.

\section{References}

1 Groen, G.P. (1974) : Uterine rupture - Review of 144 cases. Obstet. Gynaecol. 44: 682 - 687.

2 Agboola, A. (1979): Rupture of the Uterus. Nig. Med. J. 12:13

3. Oronsaye, A.U. and Asuquo, E.E. (1980): Rupture of the uterus in a Nigerian hospital. Singapore. J. Obstet. Gynaecol. $2(2): 37-42$.

4 Rotimi, E.O. and Olamijulo, J.A. (1998): Rupture of the uterus at the Lagos University Teaching Hospital, Lagos, Nigeria. West Afr. Med. J. 17 (3) : 188 - 193.

5. Beazley, J.M. (1995) : Maternal Injuries and Complications. In: Dew Hurst's Textbook of Obstetrics and Gynaecology for Postgraduates. 5th Edition. Ed. C.R., Whitefield. Blackwell Sciences Ltd. : 377 - 387.

6. Cunningham, F.G., MacDonald P.C., Gant, N.F. Leveno, K.J. et al. (1997) : Injuries to the Birth Canal. In: Williams' Obstetrics, 20th
Edition. Eds. Cunningham, F.G. et al. Appleton and Lange Pg. 543-553.

7. Lawson, J.B. (1967) : Sequelae of Obstructed labour - Rupture of the uterus. In: Obstetrics and Gynaecology in the Tropics and Developing Countries. Eds. J.B. Lawson and D.B. Stewart. E.L.B.S. and Edward Arnold Publishers Ltd. Pg. 203 - 210.

8. Konje, J.C., Odukoya, O.A. and Ladipo, O.A. (1990) : Ruptured Uterus in Ibadan - A twelve-year review. Int. J. Gynaecol. Obstet. 32: $207-213$.

9. Ghatak, D.P. (1990): Rupture of the uterus A review of 146 cases. Trop. J. Obstet. Gynaecol $8(2): 41-44$.

10. Wright, E.A. (1984) : Rupture of the gravid uterus at the University College Hospital, Ibadan - A review of 134 cases. Trop. J. Obstet. Gynaecol. $4(2): 47$ - 50.

11. Megafu, U. (1985): Factors influencing maternal survival in ruptured uterus. Int. J. Gynaecol. Obstet. 23: 473.

12. Ayangade, O. (1987) : Rupture of the Uterus: A 10 year Review. Trop. J. Obstet. Gynaecol. $8: 25-27$.

13. Harrison, K.A. (1985) : Childbearing, health and social priorities - A Survey of 22,774 consecutive hospital births in Zaria, Northern Nigeria. Br. J. Obstet. Gynaecol. 92 (suppl. 5) .

14. Balde, M.D., Breitbach, G.P., Bastert, G. (1990) : Uterine rupture - an analysis of 81 cases in Conakry/Guinea. Int. J. Gynaecol. Obstet. 32 : $223-227$.

15. O' Driscoll, K., Jackson, R.J. and Gallagher, J.T. (1969) : Prevention of Prolonged Labour. Br. Med. J. (2) : 477 - 480.

16. Hibbard, L.T. (1984) : Rupture of the Uterus in: Current Problems in Obstetrics and Gynaecology, 5th Ed. Ed. R.C., Benson. Lange Medical Publications. 76-80.

17. Rachagan, S.P., Raman, S., Balasundram, G. and Balakrishnan, S. (1991) : Rupture of the pregnant uterus - 21-year review. Aust. NZ. J. Obstet. Gynaecol. 31:37.

18. Heli, H.A., Velde, F.R. and Caims, J.M. (1984): The treatment of Rupture of the Pregnant Uterus - Analysis of 93 cases

(1) CMS UNIBEN JMBR 2006; 5 (1): 44-50 
treated in a rural hospital in Zambia. Int. J. Gynaecol. Obstet. 22: 415 - 420.

19. Makinde, O.O. and Akinyemi, S.A. (1989): Review of Ruptured Pregnant Uterus. Trop. J. Oastet. Gynaecol. 8(2) : 52 - 55.
20. Lawson, J.B. and Ajabor, L. N. (1968): Ruptured Caesarean Section Scar. J. Obstet. Gynaecol. Br. Common W. 75: 1296.

21. Ogumniyi, S.O. and Esen, U.I. (1993) : Obstetric hysterectomy in Ile-Ife. Nigeria. Int. J. Gynaecol. Obstet. 32: $23-27$. 